\title{
GRÃOS DE SOJA COMO FONTE DE UREASE NA AMONIZAÇÃO DO BAGAÇO DE CANA-DE-AÇÚCAR COM URÉIA
}

\author{
Patrícia Sarmento ${ }^{* *}$ : Rasmo Garcia ${ }^{2}$; Aureliano José Vieira Pires ${ }^{3}$; Andréia Santos Nascimento ${ }^{4}$ \\ ${ }^{1}$ Pós-Graduanda do Depto. de Produção Animal - USP/ESALQ, C.P. 9 - CEP: 13418-900 - Piracicaba, SP. \\ ${ }^{2}$ Depto. de Zootecnia - UFV, C.P. 308 - CEP: 36570-000 - Viçosa, MG. \\ ${ }^{3}$ Depto. de Tecnologia Rural e Animal (DTRA) - UESB, Pça Primavera, no 40 - CEP: 457000-000 - Itapetinga, BA. \\ ${ }^{4}$ Graduada em Zootecnia - UFV - Viçosa, MG.
}

\begin{abstract}
RESUMO: A urease é a enzima responsável pela hidrólise da uréia em amônia. A utilização de fonte de urease no tratamento de bagaço de cana-de-açúcar com uréia pode melhorar o processo da decomposição da uréia em amônia, beneficiando o tratamento de amonização e, conseqüentemente, o valor nutritivo do material. O objetivo do trabalho foi avaliar o efeito de níveis de soja crua, como fonte de urease, na amonização do bagaço de cana através da uréia. Utilizaram-se quatro níveis de soja crua $(0 ; 2,5 ; 3,75 ;$ e $7,5 \%$ da matéria seca) em bagaço de cana-de-açúcar tratado com 7,5\% de uréia (da matéria seca), armazenados por um período de 96 dias, em sacos de polietileno com capacidade de 50 litros. Foi utilizado o delineamento inteiramente casualizado com quatro níveis de soja crua e três repetições. Os teores de matéria seca, proteína bruta e hemicelulose não foram afetados pelos níveis de urease; entretanto, verificou-se efeito quadrático positivo para digestibilidade in vitro da matéria seca e linear negativo para o teor de fibra detergente neutro. A utilização de até $3,75 \%$ de soja crua na amonização com uréia propiciou melhoria na digestibilidade da matéria seca do bagaço de cana.
\end{abstract}

Palavras-chave: amonização, bagaço de cana-de-açúcar, valor nutritivo, urease, uréia

\section{SOYBEAN GRAIN AS UREASE SOURCE FOR THE SUGARCANE BAGASSE AMMONIATION WITH UREA}

\begin{abstract}
The urease is the responsible enzyme for hidrolisis of urea into ammonia. The use of a urease source for the treatment of sugarcane bagasse with urea can improve the urea decomposition process into ammonia, improving the nutritious value of the material. The objective of this work was to evaluate the effect of the level of ground whole soybean as a urease source for sugarcane bagasse ammoniation through urea. Four levels of whole soybean $(0,2.5,3.75$ and $7.5 \%$ on dry matter basis), were added to sugarcane bagasse treated with $7.5 \%$ of urea (on dry matter basis) and stored during 96 days in plastic bags $(50 \mathrm{~L}$ ). A complete randomized design with four treatments and three replicates was used. Dry matter, crude protein and hemicellulose contents were not affected by urease levels, there was, however, a positive quadratic effect for in vitro dry matter disappearance and a negative linear effect for neutral detergent fiber disappearance. The use of $3.75 \%$ of whole soybean in the ammoniation through urea was beneficial for the improvement of the dry matter digestibility of sugarcane bagasse.

Key words: ammoniation, sugarcane bagasse, nutritive value, urease, urea
\end{abstract}

\section{INTRODUÇÃO}

O Brasil tornou-se o maior produtor mundial de álcool, com cerca de 12 bilhões de litros/ano e 8,500,000 t/ano de açúcar, devido à implantação do Programa Nacional do Álcool, iniciado na década de 1970 (Bürgi, 1995). Em decorrência dessa crescente atividade sucro-alcooleira, vários pesquisadores têm conduzido diversos estudos de utilização dos subprodutos da cana, como levedura, vinhaça, torta de filtro, ponta de cana e bagaço, sendo este último quantitativamente o mais importante.

O bagaço in natura é um produto fibroso resultante do esmagamento da cana-de-açúcar, para obtenção de açúcar, álcool ou aguardente (Santana \& Souza, 1984). Apesar de ser considerado um alimento de baixa qualidade para ruminantes, rico em fibra, baixo conteúdo celular, baixa digestibilidade, pobre em proteína e minerais (Santos, 1990), seu uso será eficiente, se o valor nutritivo for melhorado por meio de tratamento químico e/ou físico.

O tratamento via amonização promove aumento nos teores de nitrogênio não-protéico e atua na fração fibrosa causando solubilização de parte da hemicelulose, aumentando, assim, a digestibilidade e o consumo de volumosos de baixa qualidade (Garcia, 1992), além de atuar como fungiostático no material amonizado (Campos, 1995; Pires et al., 1999). A teoria que explica o efeito da amônia sobre a fração fibrosa das forragens foi denominada de "amonólise" (Tarkov \& Feist, citados por Pires, 1995), que baseia-se na reação entre a amônia e um éster, a qual produz uma amida. As ligações ésteres entre a hemicelulose e a lignina com grupos de carboidratos são rompidas com a conseqüente formação de amida. Buettner et al., citados por Pires (1995) verificaram que a molécula de amônia, por meio de uma 
reação de amonólise, promoveu rompimento de ligações ésteres com conseqüente formação de amida, influenciando positivamente na digestibilidade do feno tratado.

Teixeira (1990) constatou aumento nos teores de proteína bruta de 153 e $273 \%$ na palha de milho mais sabugo tratada com 1,5 e $3 \%$, respectivamente, comparada ao material não tratado. Reis et al. (1990) obtiveram valores de 0,$7 ; 1,2$ e 1,3\% de proteína bruta e 84,$1 ; 79,6$ e $80,0 \%$ de fibra em detergente neutro para os níveis de 0,$0 ; 1,5$ e 3,0\% de amônia anidra (base MS) em feno de capim-braquiária (Brachiaria decumbens Stapf). Bonjardim et al. (1992), aplicando níveis de 0,0; 1,5 e $3,0 \%$ de amônia anidra (base MS) em feno dos capins Coast cross (Cynodon dactylon L. Pers. cv. Coat cross) e Estrela da África (Cynodon plectostachhyus K. Schum), constataram diminuição no teor de fibra em detergente neutro de 76,9 para $70,5 \%$ e aumento da digestibilidade in vitro da matéria seca de 39,6 para $57,8 \%$.

Em certas regiões, a amônia anidra não está disponível no mercado. A uréia, por outro lado, passa a ser uma alternativa, por ser um produto de alta disponibilidade e de menor risco à intoxicação humana (Garcia \& Neiva, 1994).

A uréia, quando decomposta, forma amônia, como é visto a seguir (Garcia \& Neiva, 1994): $\mathrm{NH}_{2} \mathrm{CONH}_{2}$ $+\mathrm{H}_{2} \mathrm{O}=>2 \mathrm{NH}_{3}+\mathrm{CO}_{2}$.

Garcia \& Neiva (1994) mencionam que na amonização com uréia há necessidade, em algumas situações, de adição de fonte de urease que garanta melhor conversão de uréia em amônia e, conseqüentemente, eficiente amonização. Os mesmos autores sugeriram o uso de grão de soja moído como fonte de urease, misturado à uréia. No entanto, Cândido et al. (1998) não constataram efeito da adição de soja crua como fonte de urease, na dosagem recomendada por Jayasuriya \& Pearce (1983), que utilizaram a relação soja crua:uréia de 1:5 na amonização de bagaço de cana, com níveis de 2, 4, 6 e $8 \%$ de uréia (base MS). Portanto, por causa da carência de informações científicas nessa área torna-se necessária a avaliação do uso de soja crua como fonte de urease na amonização de bagaço de cana com uréia.

$\mathrm{O}$ objetivo deste trabalho foi avaliar o efeito de níveis de fonte de urease na composição químicobromatológica e na digestibilidade in vitro da MS do bagaço de cana tratado com uréia.

\section{MATERIAL E MÉTODOS}

O trabalho foi conduzido no Departamento de Zootecnia da Universidade Federal de Viçosa. A canade-açúcar foi beneficiada na Usina de Rio Branco (MG) e o subproduto (bagaço), transportado para Viçosa e armazenado em local coberto. Posteriormente, o bagaço foi ensacado (8 $\mathrm{kg}$ na matéria original/saco) e misturado com $7,5 \%$ de uréia (base MS), em diferentes níveis de soja crua moída $(2,5 ; 3,75$ e $7,5 \%$ base MS) sendo a relação soja:uréia de 1:3; 1:2; e 1:1, respectivamente. Adotou-se o nível de $7,5 \%$ de uréia com base na matéria seca em função de resultados promissores encontrados por Sarmento et al. (1999) na amonização de bagaço de cana-de-açúcar com a utilização desse mesmo nível. Outros trabalhos de amonização de volumosos de baixa qualidade recomendam que sejam utilizadas de 3 a $4 \%$ de amônia anidra (82\% N) (Garcia \& Neiva, 1994) o que eqüivale a 5,58 e $7,28 \%$ de uréia $(45 \% \mathrm{~N})$, respectivamente.

Logo após a adição de uréia e dos níveis de soja crua, os sacos (50 L) foram hermeticamente fechados, cobertos por lona plástica e deixados ao ambiente por período de 96 dias. Após esse período de amonização, os sacos foram abertos e deixados dois dias em aeração, seguido de homogeneização e coleta de amostras para subseqüentes análises químico-bromatológicas. As amostras foram secas à temperatura de $40^{\circ} \mathrm{C}$ para minimizar perdas de amônia por volatilização (Silva, 1990).

A composição bromatológica do grão de soja e do bagaço de cana não-tratado está apresentada na TABELA 1.

As análises de matéria seca (MS), nitrogênio total (NT), fibra em detergente neutro (FDN) e hemicelulose foram realizadas de acordo com os procedimentos descritos por Silva (1990). Foram também realizadas as análises de digestibilidade in vitro da MS (DIVMS), utilizando-se a técnica de Tilley \& Terry (1963).

Utilizou-se a técnica de dedução matemática da contribuição dos nutrientes provenientes da soja crua (TABELA 1) para que não interferissem no efeito dos níveis de urease presentes na soja, sobre a composição do bagaço amonizado com uréia. Os resultados químicobromatológicas do bagaço de cana tratado com uréia e com crescentes níveis de urease, na qual retirou-se 0 efeito dos constituintes da soja na composição do bagaço, estão apresentados na TABELA 3.

Os dados percentuais para retenção de nitrogênio (RN) no bagaço de cana-de-açúcar tratado com uréia, em relação ao não amonizado, foram obtidos com base no procedimento adotado por Campos (1994) e Pires et al. (1999):

sendo:

$$
\mathrm{RN}(\%)=[(\% \mathrm{NA}-\mathrm{NB}) \div(\% \text { uréia } \times 0,45)] \times 100
$$

TABELA 1 - Composição química da soja crua e do bagaço de cana-de-açúcar.

\begin{tabular}{lcrrrr}
\hline & MS & PB & FDN & He micelulose & DNMS \\
\hline & -1 & - & - \\
Bagaço & 62,28 & 2,36 & 91,08 & 22,22 & 31,49 \\
Soja crua* & 90,60 & 42,50 & 18,99 & 8,41 & 82,80 \\
\hline
\end{tabular}

${ }^{*}$ Atividade ureolítica: $500 \mathrm{mg}$ uréia $\mathrm{g}^{-1} \mathrm{~h}^{-1}$ a $37^{\circ} \mathrm{C}$ (Jayasuriya \& Pearce, 1983).

MS = matéria seca; $\mathrm{PB}$ = proteína bruta; FDN = fibra em detergente neutro; DIVMS = digestibilidade in vitro da matéria seca. 
$\mathrm{RN}(\%)=$ retenção de nitrogênio expressa em porcentagem do nitrogênio adicionado; \%NA = porcentagem de $\mathrm{N}$ total no material amonizado; \%NB = porcentagem de $\mathrm{N}$ total no material não-amonizado; \%uréia = porcentagem de uréia utilizada no tratamento e $0,45=$ valor percentual de $\mathrm{N}$ na uréia .

O delineamento experimental foi o inteiramente casualizado com quatro níveis de soja crua e três repetições. Foi utilizado o programa estatístico SANEST-USP (Sarriés et al., 1993) para testar a hipótese de efeito dos níveis de soja crua, utilizandose $o$ teste $F$ na análise de variância. Para observar o efeito dos níveis de soja crua em relação às variáveis analisadas, foi utilizada a análise de regressão polinomial.

\section{RESULTADOS E DISCUSSÃO}

Observa-se na TABELA 2, na qual não se retirou o efeito dos constituintes da soja crua dos tratamentos, maiores teores de MS, PB e DIVMS e menores de FDN, quando comparados com os resultados da TABELA 3. Dessa maneira, quando não se retirou os efeitos dos constituintes da soja crua, houve o confundimento da composição da soja nos resultados. No entanto, quando se eliminou o efeito da soja (TABELA 3), foi possível distinguir os efeitos da urease presentes no grão de soja sobre a conversão da uréia em amônia no bagaço tratado com crescentes níveis de soja crua.

A aplicação de crescentes níveis de soja crua não alterou $(P>0,05)$ os teores de MS e $P B$ do bagaço de cana tratado com uréia (TABELA 3). Resultados semelhantes, em relação ao teor de $\mathrm{PB}$, foram encontrados por Hassoun et al. (1990) e Cândido et al. (1998) trabalhando com bagaço de cana amonizado com uréia. Uma vez que o teor de PB engloba o teor de nitrogênio protéico e não protéico (NNP) não foi possível detectar o efeito da adição de soja crua sobre essa variável.

Por outro lado, houve aumento no teor de PB do bagaço amonizado em $76 \%$ em relação ao teor de $\mathrm{PB}$ do bagaço original. Isso pode ser explicado pela adição de NNP através da uréia. Nunes (1995) mencionou que para a manutenção da microbiota ruminal exige-se 0 mínimo de $1 \%$ de nitrogênio na dieta $(6,25 \%$ de $\mathrm{PB})$. Portanto, a amonização em resíduos agro-industriais é benéfica por adicionar nitrogênio ao material, o que favorece o crescimento dos microorganismos ruminais que possuem habilidade de utilizar a $\mathrm{NH}_{3}$ na síntese protéica (Teixeira, 1992).

A RN do bagaço de cana amonizado foi de $35,3 \%$. Pires et al. (1999) relataram que a RN diminui à medida que ocorre aumento na dose de amônia anidra aplicada à quirera de milho, tendo encontrado os valores de 61,$9 ; 39,0$ e $31,2 \%$ nas doses de 1,2 e
$3 \%$ de amônia anidra, respectivamente. Srivastava \& Mowat (1980) encontraram RN de $35 \%$ quando utilizaram dose de $2 \%$ de amônia anidra em espiga de milho.

Observou-se diminuição no teor de FDN $(P<0,05)$, em função dos níveis de soja crua adicionados (TABELAS 3 e 4). No entanto, esse resultado não está de acordo com os observados por Brown \& Adjei (1995) e Cândido et al. (1998). O resultado encontrado no presente trabalho pode ser atribuído à ação positiva da urease, presente no grão de soja, sobre a conversão da uréia em amônia, contribuindo, assim, no processo de amonização, por intermédio da solubilização parcial da hemicelulose. Decréscimos dos teores de FDN de materiais amonizados têm sido observados por vários autores (Pires, 1995, Cândido et al., 1998 e Sarmento et al., 1999).

No entanto, os teores de FDN do bagaço tratado podem ter sido subestimados devido à utilização do método de dedução matemática dos nutrientes provenientes da soja não ter considerado o efeito da amônia sobre o FDN da soja crua. Da mesma maneira, o teor de hemicelulose do bagaço tratado pode ter sido subestimado e a digestibilidade da MS superestimada. No entanto, material com baixo teor de FDN e alta digestibilidade apresenta pequena alteração nesses

TABELA 2 - Teores percentuais médios de matéria seca (MS), proteína bruta (PB), fibra em detergente neutro (FDN) e digestibilidade in vitro da matéria seca (DIVMS) do bagaço ${ }^{1}$ de cana-de-açúcar quando não se removeu o efeito da participação dos constituintes da soja crua.

\begin{tabular}{cccc}
\hline MS & PB & FDN & DNMS \\
\hline 61,45 & 10,89 & 84,27 & 50,75 \\
\hline
\end{tabular}

'Bagaço de cana tratado com 7,5\% de uréia e armazenado por 96 dias.

TABELA 3 - Teores médios de matéria seca (MS), proteína bruta (PB), hemicelulose, fibra em detergente neutro (FDN) e digestibilidade in vitro da matéria seca (DIVMS) do bagaço de cana-de-açúcar², em função dos níveis de soja crua, retirando-se a participação dos constituintes da soja.

\begin{tabular}{|c|c|c|c|c|c|}
\hline $\begin{array}{l}\text { Níveis de } \\
\text { soja crua }\end{array}$ & MS & PB & Hemicelulose & FDN & DIVMS \\
\hline \multicolumn{6}{|c|}{ - } \\
\hline 0 & 60,85 & 10,02 & 23,29 & 86,24 & 46,51 \\
\hline 2,5 & 60,36 & 9,86 & 22,39 & 84,36 & 49,57 \\
\hline 3,75 & 59,15 & 10,15 & 21,63 & 83,00 & 50,15 \\
\hline 7,5 & 57,75 & 9,18 & 21,69 & 81,20 & 46,94 \\
\hline Média & 59,53 & 9,08 & 22,25 & 83,70 & 48,29 \\
\hline CV (\%) & 3,19 & 5,74 & 4,50 & 1,09 & 2,69 \\
\hline$F^{3}$ & $1,60^{\mathrm{ns}}$ & 0,79 ns & $0,23^{n s}$ & $16,36^{*}$ & $5,67^{\star}$ \\
\hline
\end{tabular}

${ }^{2}$ Bagaço de cana tratado com $7,5 \%$ de uréia e armazenado por 96

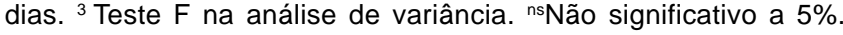
${ }^{*}$ Significativo a $5 \%$. 
TABELA 4 - Fibra detergente neutro (FDN) e digestibilidade in vitro da matéria seca (DIVMS) do bagaço ${ }^{4}$ de cana, em função dos níveis de soja crua $(X)$, retirando-se a participação dos constituintes da soja.

\begin{tabular}{|c|c|c|}
\hline VARIÁVEL & EQUAÇÕES & $\mathrm{R}^{2}$ \\
\hline DN (\%) & $86,016845-0,6739909 X$ & $0,9746^{*}$ \\
\hline DINS (\%) & $46,487958+1,8545399 X-0,2392175 X 2$ & $0,9991^{*}$ \\
\hline
\end{tabular}

${ }^{4}$ Bagaço de cana tratado com $7,5 \%$ de uréia e armazenado por 96 dias. ${ }^{\star}$ Significativo a $5 \%$.

componentes quando amonizado (Cândido et al., 1999 e Pires et al., 1999). Garcia \& Neiva (1994) mencionaram que o efeito da amonização é altamente dependente da qualidade do material avaliado. Assim, pode-se especular que o provável efeito da amonização sobre a soja crua talvez seja desprezível nesse contexto.

Houve efeito $(P<0,05)$ dos níveis de soja crua na DIVMS do bagaço amonizado com uréia (TABELA 3). O melhor ajuste no modelo matemático para DIVMS, em função dos níveis crescentes de soja crua adicionados, foi o quadrático (TABELA 4). O efeito positivo da adição da soja-grão pode ser atribuído, provavelmente, à contribuição da urease no aumento da eficiência do processo de amonização do bagaço via uréia. Aumentos na DIVMS são resultantes da ação da amônia sobre a hemicelulose, ocorrendo expansão da mesma, facilitando, assim, o ataque da parede celular pelos microrganismos do rúmen (Grotheer, 1985).

No entanto, em estudos realizados por Williams et al. (1984) e Wanapat et al. (1985), não se observou efeito na DIVMS, com a adição de 5 e $0,5 \%$ de farelo de soja (fonte de urease), respectivamente, sobre a amonização via uréia de palha de cevada. Tal fato pode ser atribuído, provavelmente, à perda da atividade da enzima da soja durante seu processamento (Jayasuriya \& Pearce, 1983).

A DIVMS do bagaço tratado com uréia sem soja crua aumentou em $32,3 \%$ em relação ao bagaço original. Por outro lado, nos níveis de 2,5 e $3,75 \%$ de fonte de urease ocorreram pequenos aumentos na DIVMS $(6,2 \mathrm{e}$ $7,3 \%$, respectivamente) em relação ao bagaço amonizado sem soja crua (TABELA 3). Essa pequena magnitude do efeito de fonte de urease em relação ao efeito da uréia sem a soja crua sugere a provável existência de urease no bagaço de cana que garanta a conversão da uréia em amônia. Diante disso, é possível inferir que somente a utilização de uréia, ao nível de $7,5 \%$, na amonização do bagaço de cana apresenta alto potencial para aumentar a digestibilidade desse material e que o uso de soja crua, como fonte de urease, não seja imprescindível no tratamento do bagaço de cana com uréia. Hassoun et al. (1990) e Cãndido et al. (1999) obtiveram aumentos no teor de DIVMS em torno de 20,5 e $14,9 \%$, respectivamente, no tratamento do bagaço de cana com 8,8 e $8,0 \%$ de ureia, sem o uso de fonte de urease.
A DIVMS do bagaço no nível de $7,5 \%$ de grão de soja apresentou-se semelhante ao nível zero de soja (TABELA 3), com valores de 46,5 e $46,9 \%$ respectivamente. Isso pode ser explicado pela provável contribuição do alto teor do óleo da soja na diminuição da fermentação microbiana e conseqüente decréscimo da DIVMS. Observações semelhantes foram encontradas por Erickson \& Barton (1987). Van Soest (1994) afirmou que o excesso de ácidos graxos insaturados pode causar profunda alteração no balanço da fermentação, por intermédio da supressão das bactérias metanogênicas e celulolíticas, comprometendo, assim, a digestibilidade do material.

\section{CONCLUSÃO}

A aplicação de níveis de soja crua no bagaço de cana tratado com uréia, quando se removeu o efeito da participação dos constituintes da soja-grão, não alterou os teores de MS, PB e hemicelulose do bagaço de cana-de-açúcar. Por outro lado, o teor de FDN do bagaço diminuiu com a adição de soja. A adição de soja crua até $3,75 \%$ (base MS) melhora a DIVMS do bagaço de cana tratado com uréia, no entanto altos níveis de soja crua $(7,5 \%)$ podem causar decréscimo da DIVMS. A utilização de uréia na amonização do bagaço, sem urease, proporcionou resultados mais expressivos do que com o uso de soja crua, sugerindo que no tratamento do bagaço de cana com uréia o uso de fonte urease não é imprescindível.

\section{REFERÊNCIAS BIBLIOGRÁFICAS}

BONJARDIM, S.R.; REIS, R.A.; RODRIGUES, L.R.A.; PEREIRA, J.R.A. Avaliação da qualidade dos fenos de gramíneas tropicais armazenados com diferentes níveis de umidade e tratados com amônia. Revista Brasileira de Zootecnia, v.21, p.866-873, 1992.

BROWN, W.F.; ADJEI, M.B. Urea ammoniation effects on the feeding value of guineagrass (Panicum maximum) hay. Journal Animal Science, v.73, p.3085 - 3093, 1995.

BÜRGI, R. Cana-de-açúcar. In: SIMPÓSIO SOBRE NUTRIÇÃO DE BOVINOS, 6., Piracicaba, 1995. Anais. Piracicaba: FEALQ, 1995. p.153-170.

CAMPOS, M.C.L. Níveis de amônia anidra e períodos de amonização sobre a composição químico-bromatológiaca e degradabilidade dos fenos de alfafa (Medicago sativa L.) e coast-cross (Cynodon dactylon (L.) Pers. cv. coastcross) com alta umidade. Viçosa, 1995. 135p. Dissertação (Mestrado) Universidade Federal de Viçosa.

CÂNDIDO, M.J.D.; NEIVA, J.N.M.; PIMENTEL, J.C.M.; VASCONCELOS, V.R.; SAMPAIO, E.M.; NETO, J.M.; ARAÚJO, E.F. Amonização do bagaço de cana-de-açúcar. In: CONGRESSO BRASILEIRO DE ZOOTECNIA, Botucatu, 1998. Anais. Botucatu: SBZ, 1998. p.424-426.

CÂNDIDO, M.J.D.; NEIVA, J.N.M.; PIMENTEL, J.C.M.; VASCONCELOS, V.R.; SAMPAIO, E.M.; NETO, J.M. Avaliação do valor nutritivo do bagaço de cana-de-açúcar amonizado com uréia. Revista Brasileira de Zootecnia, v.28, p.928-935, 1999. 
ERICKSON, P.S.; BARTON, B.A. Whole soybeans for market lambs. Journal Animal Science, v.64, p.1249-1260, 1987.

GARCIA, R. Amonização de forragens de baixa qualidade e a utilização na alimentação de ruminantes. In: SIMPÓSIO SOBRE UTILIZAÇÃO DE SUBPRODUTOS AGROINDUSTRIAIS E RESÍDUOS DE COLHEITA NA ALIMENTAÇÃO DE RUMINANTES, São Carlos, 1992. Anais. São Carlos: Embrapa, 1992. p.83-97.

GARCIA, R.; NEIVA, J.N.M. Utilização da amonização na melhoria da qualidade de volumosos para ruminantes. In: SIMPÓSIO NORDESTINO DE ALIMENTAÇÃO DE RUMINANTES, 5., Salvador, 1994. Anais. Salvador: Sociedade Nordestina de Produção Animal, 1994. p.41-61.

GROTHEER, M.D.; CROSS, D.L.; GRIMES, L.W.; CALDWELL, W.J.; JOHNSON, L.J. Effect of moisture level and injection of ammonia on nutritive quality and preservation of coastal bermudagrass hay. Journal Animal Science, v.61, p.1370-1377, 1985.

HASSOUN, P.; GEOFFROY, F.; SAMINADIN, G.; PRIOR, P.; BERAMIS, M. Studies on the ammoniation of sugar-cane bagasse by urea. effects of moisture, urea levels, urease source and treatment periods on composition, in vitro dry matter digestibility and evolution of ureolytic bacteria. Animal Feed Science and Techonology, v.29, p.113-129, 1990.

JAYASURIYA, M.C.N.; PEARCE, G.R. The efect of urease enzyme on treatment time and the nutritive value of straw treated with ammonia. Animal Feed Science and Technology, v.8, p.271-281, 1983.

NUNES, I.J. Nutrição Animal. Belo Horizonte: ISBN, 1995. 334p.

PIRES, A.J.V. Efeito da amônia anidra sobre a conservação e composição químico-bromatológica da quirela de milho (Zea mays L.) com alta umidade. Viçosa, 1995, 70p. Dissertação (Mestrado) - Universidade Federal de Viçosa.

PIRES, A.J.V.; GARCIA, R.;CECON, P.R.; NEIVA, J.N.M.; SARMENTO, P. Amonização da quirera de milho com alta umidade. Revista Brasileira de Zootecnia, v.28, p.1186-1193, 1999.

REIS, R.A.; GARCIA, R.; SILVA, D.J.; QUEIROZ, A.C.; FERREIRA, J.Q. Efeitos da aplicação de amônia anidra sobre a digestibilidade do feno do capim-braquiária (Brachiaria decumbens Stapf). Revista Brasileira de Zootecnia, v.19, p.201-208, 1990.
SANTANA, J.; SOUZA, S.O.A. Subprodutos da cana-de-açúcar. Informe Agropecuário, v.10, p.22-27, 1984.

SANTOS, F.A.P. O bagaço de cana-de-açúcar tratado sob pressão de vapor como alternativa para a alimentação de bovinos na entressafra das pastagens. In: REUNIÃO ANUAL DA SOCIEDADE BRASILEIRA DE ZOOTECNIA, 25., Campinas, 1990. Anais. Campinas, 1990. 203p.

SARMENTO, P.; GARCIA, R.; PIRES, A.J.V.; NASCIMENTO, A.S. Tratamento do bagaço de cana de açúcar com uréia. Revista Brasileira de Zootecnia, v.28, p.1203-1208, 1999.

SARRIÉS, G.A.; ALVES, M.C.; OLIVEIRA, J.C.V. Sanest. Piiracicaba: USP, ESALQ, CIAGRI, 1993. 57p. (Série Didática, 6)

SILVA, D.J. Análise de alimentos: métodos químicos e biológicos. 2.ed. Viçosa, UFV, 1990, 165p.

SRIVASTAVA, V.K.; MOWAT, D.N. Preservation and processing of whole high moisture shelled corn with ammonia. Canadian Journal of Animal Science, v.60, p.683-688, 1980.

TEIXEIRA, J.C. Nutrição de ruminantes. Lavras: FAEPE, 1992. $239 p$.

TEIXEIRA, J.R.C. Efeito da amônia anidra no valor nutritivo da palha de milho mais sabugo e do capim-elefante (Penninsetum purpureum shum) cv cameroom fornecidos a novilhos nelore em confinamento. Viçosa, 1990, 97p. Dissertação (Mestrado) - Universidade Federal de Viçosa.

TILLEY, J.M.A.; TERRY, R.A. A two technique for the in vitro digestion of forage crops. Journal of the Britsh Grassland Society, v.18, p.104-111, 1963.

VAN SOEST, P. Nutritional ecology of the ruminant. 2.ed. New York: Cornell University Press, 1994, 476p.

WANAPAT, M.; SUNDSTOL, F.; GARMO, T.H. A comparation of alkali treatment methods to improve the nutritive value of straw. I. digestibility and metabolizability. Animal Feed Science and Technology, v.12, p.295-309, 1985.

WILLIAMS, P.E.V.; INNES, G.M.; BREWER, A. Ammonia treatment of straw via the hydrlysis of urea: II. Additions of soya bean (urease), sodium hydroxide and molasses; efects on the digestibility of urea-treated straw. Animal Feed Science and Technology, v.11, p.115-124, 1984.

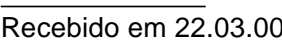

